\title{
Design Thinking as a Strategy for Marketing Confectionery Products: A Case Study of Cocoa Processing Company-Ghana
}

\author{
Kofi Poku (Corresponding author) \\ Senior Lecturer, School of Business, Department of Marketing and Corporate Strategy \\ Kwame Nkrumah University of Science and Technology, Ghana \\ Email: kofi_poku1@yahoo.comＴel: 233-24-401-6839 \\ Martin Owusu Ansah \\ Market Research Consultant, P.O. Box KS 8673, Adum, Kumasi, Ghana \\ E-mail: owusumartin97@yahoo.co.ukＴel: 233-24-459-6606
}

Received: March 13, 2014 Accepted: April 7, 2014 Published: June 19, 2014

doi:10.5296/bmh.v2i1.5281～URL: http://dx.doi.org/10.5296/bmh.v2i1.5281

\begin{abstract}
This research looked at a shift from plain technology improvements to real endeavours in order to address the needs of consumers and to generate powerful and sustainable solutions that could tackle the current and future challenges at Cocoa Processing Company through Design Thinking. The main objective was to investigate how Design Thinking can be used by Cocoa Processing Company as a critical strategic tool for the marketing of their confectionery products.

The research aimed at investigating how C.P.C used design thinking in its market strategies, to help increase its sales through discovery and creativity, bearing in mind the encouragement of customer satisfaction through design thinking and also differentiate its product from competitors. Primary and secondary data were used in collecting the data. The primary data was gathered through interviews with personnel from Marketing, R\&D and Production departments of CPC and customers. The secondary data was information from Cocoa Processing Company's web pages, annual reports and previous related research works on design thinking done by others on the Internet. The research population was ten and hence all were chosen as the sample size. Purposive sampling technique was used in gathering the data.
\end{abstract}




\section{Macrothink}

Business and Management Horizons

ISSN 2326-0297

2014, Vol. 2, No. 1

The data was analysed using pattern matching which is also known as analytic technique. The study revealed that the organisation made use of design thinking in their marketing strategies in differentiating products from its competitors. The integration of the various departments within the organization also contributed in marketing the company's products. It was recommended for CPC to use the Design Thinking Processes to assess its current design capabilities and identify the gaps in their design process. It was recommended for C.P.C to liaise with students with background in design, business and technology in the form of multidisciplinary teams to help improve marketing activities in the organisation.

Keywords: Confectionery product, Design thinking, Pattern matching, Concept visualisation 


\section{Introduction}

In a world of continuous changes, where markets mature faster and everyone is affected by information overload, organizations need marketing strategies that would serve as the prime driver of sustainable competitive advantage. To unlock such opportunities, there is the need for the use mind sets and protocols from the field of design to make out unarticulated wants and deliberately imagine, envision, and spawn futures.

In the past, design was a downstream step in the product development process, aiming to enhance the appeal of an existing product. Today, however, organizations ask designers to imagine solutions that meet explicit or latent needs and to build upstream entire systems that optimize customer experience and satisfaction. Instead they should see it as an opportunity to optimize customer satisfaction and company profitability and value as well as enhance products, environment, communications and identity (Kotler \& Rath, 1984).

Design issues force a company to focus on the consumers' wants and needs and the product's ability to satisfy them, instead of on the processes within the organization. The objective of using design as a strategic marketing tool is to create total satisfaction for the consumer which translates into profits for the company. This is termed design thinking. Total satisfaction is accomplished by communicating information about products, services and organizations to consumers, suppliers, employees and shareholders through product design, information design, environment design and corporate identity design.

In the last five years, design thinking has emerged as the quickest organizational path to innovation and high-performance, changing the way creativity and commerce interact (Brown \&Wyatt, 2010).

According to Fraser (2009), the greatest payout of design thinking lies in the design of strategies and business models for organizational performance that creates both economic and human value. Broadening the definition of design, she argues that it can be the path to understanding stakeholder needs, the tool for visualizing new solutions, and the process for translating cutting-edge ideas into effective strategies.

Fraser (2009) illustrates three iterative gears in business design. Anchored in the needs of stakeholders, they apply deep user understanding to stimulate high-value conceptual visualizations and extract from these the strategic intent needed to reform business models. 
Empathy and Deep User Understanding

(A deep dive with a broad lens)

\section{Concept Visualization}

(Ideation, Prototyping and user evaluation)

\section{Strategic Business Design}

(Activity system design and evaluation)

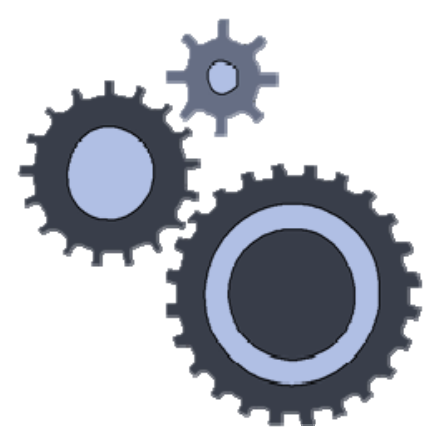

Figure 1. The gears of business design

Source: Heather Fraser. (2009). Designing Business: New Models for Success. Design Management Review. Vol. 20, No. 2, pp. 55-65.

\section{a. Gear One: Deep User Understanding.}

The first step is to turn the telescope around to reframe the organization and view its business entirely through the eyes of the customer (and, of course, other critical stakeholders). It is necessary to look beyond the direct use of an organization's products or services to the contexts in which they are located, in terms of the activities surrounding their utilization, to gain deeper insight and broader behavioural and psychographic perspectives. It is also critical to understand the "whole person" engaged in any given activity — not just what they do, but how they feel and how their needs surrounding their activities link to other parts of their lives.

\section{b. Gear Two: Concept Visualization.}

With renewed empathy and a broader set of criteria for innovation serving as springboard, creativity can be unleashed and move through multiple-prototyping and concept enrichment, ideally with users. It is vital to look beyond what is to what could be, using imagination to generate altogether new-to-the-world solutions. At this stage, there are no constraints, only possibilities. Engaging all functions and disciplines on the team infuses ideas into the process, fortifies team alignment, and prepares the traction that will lock down strategies and activate them later.

\section{c. Gear Three: Strategic Business Design.}

With well-defined, user-inspired solutions at hand the third gear aligns broad concepts with future reality. This entails prototyping business models to integrate their parts and assess the impact of the activity system as a whole. It is imperative to identify what will drive the success of the solutions; prioritize what activities an organization must undertake to deliver related strategies; define relationships strategically, operationally, and economically; and determine what net impacts the new business models will have. 
Companies that integrate the principles of design thinking in their innovation processes often share a certain mindset or are striving to cultivate a more creative and human-centred company culture.

Ghana's Cocoa Processing Company is one of the largest producers of cocoa products in the world. Though it has one of its core values as aiming towards its customers delight and not just mere satisfaction, the company still faces the challenge of low patronage of its confectionery products on the Ghanaian market causing a drastic fall in sales. Their products are well known and their prices moderate but anecdotal evidence suggest that Ghanaians prefers the exported confectionery products because of a series of flaws in the overall design of their system. Most of CPC's confectionery products are either in medium or large sizes that are bigger than most average consumers will need or can afford. The producer of the best cocoa products, CPC, has missed the opportunity to design products which best fits the natives of its country of origin because it failed to consider the culture and needs of the people living in Ghana.

This missed opportunity, although an obvious omission in hindsight is all too common. Time and again, initiatives falter because they are not based on the client's or customer's needs and have never been prototyped to solicit feedback. Sometimes even when researchers do go into the fields, they may enter with perceived notions on what needs and solutions are. This flawed approach remains the norm in most business sectors. There is therefore the need for organizations to come up with systematic solutions that are grounded in the clients or customers' needs to help curb these challenges. This is where many approaches founder, but it is where design thinking, a new approach to creating solutions excel.

\section{Problem Statement}

Throughout the years, several strategies, methods, remedies and theories have been accepted and tried by managers in order to achieve greater growth rates and profits for their companies. However, being exposed to unprecedented change, rapid transformation of knowledge and resources has changed the rules of the traditional business game (Fraser, 2009). It is a shift from plain technology improvements to real endeavours in order to address the needs of consumers, to generate powerful and sustainable solutions that could tackle the current and future challenges by looking, sensing and creating beyond immediate contexts and having a visionary mind set (Brown, 2008; Vogel, 2009).The idea of using Design thinking in marketing activities other than the use of design principles in marketing confectionary products which is not a common strategy has necessitated this research to identify the significant role design thinking plays in our marketing strategy as a way of improving the company's fortune

\section{Research Objectives}

The objectives of the study were to :

- $\quad$ Assess how C.P.C used design thinking in its market strategies

- Investigated how through design thinking CPC differentiated its product from competitors 


\section{Macrothink}

- Assess how C.P.C developed deep consumer insights on the products it offers

- Identify the level of integration within the various departments at C.P.C

\section{Research Questions}

The research was guided by the following questions:

- How did CPC use design thinking in its market strategies?

- What differentiated CPC products from that of its competitors?

- How did CPC develop deep consumer insight on the product it offers?

- What was the level of integration within the various departments at CPC?

\section{Significant of the Study}

The study served as a strategic tool that management could use for creating value and also retaining customers within Ghanaian organization, especially those of CPC-Ghana.

It also provided reliable and useful information that served as a reference material for organisations in Ghana, either service or products. Also, through this study, the relationship between marketers and designers were strengthened and that brought value and satisfaction to both the consumer and the organization. The outcome of the study significantly advanced the frontier of knowledge and added to existing academic literature on design thinking as a strategy of marketing in Ghanaian organizations.

\section{Literature Relevant to the Study}

This chapter reviewed concepts and themes on Marketing Strategies, Design, Design Thinking, Design Management and the Value of Design as a strategic tool.

\subsection{Strategy}

The concept of strategy has been viewed in several ways by different authors.

Definition given by Chandler (1962) posits that strategy is the determination of the basic long-term goals of an enterprise, and the adoption of courses of actions and the allocation of resources necessary to carry out these goals. From the above definition, Chandler saw Strategy as a means of establishing the purpose of the organizational in terms of its long-term objectives, action programs, and resource allocation priorities.

Strategy is the fundamental pattern of present and planned objectives, resource development and interactions of an organization with markets, competitors and other environmental factors.( Mullins, Walker, Boyd, \& Larreche, 2002) For this reason a good strategy should always specify: a) What is to be accomplished; b) Where- the product, markets or industries that are to be focused and c) How- resources and activities that will be allocated to each market/product to gain sustainable advantage.

In order to be successful, a strategy whether driven by cost, technology, distribution, service or other competitive advantage of the firm, has to be consistent with the consumer's needs, 
perception and preferences.

\subsection{Marketing Strategies}

According to Kotler (1997), marketing strategies are the broad principles by which the business unit expects to achieve its marketing objectives. It consists of basic decisions on total marketing expenditure, marketing mix and marketing allocation. Bovee and Thill (1992) also defined marketing strategy as an organisations general plan for choosing a target and succeeding within that target market through product, pricing, distribution and promotional choices. This implies that companies with strong marketing cultures develop strategies built around the satisfaction of its customers, which might not usually be the same in the case of production or sales- oriented companies. In the words of Bearden, Ingram and Laforge (1995) marketing strategies consists of the selection of a target market and the development of a marketing mix to satisfy the needs of that market. It usually consists of decisions in four basic areas: product (development if a product, service, or idea to exchange), pricing (what to charge for the exchange) and distribution (how to get the product, service or idea to the target market to consummate the exchange).

\subsection{Elements of the Marketing Mix}

Marketing strategies are means of designing and integrating various elements of the marketing mix in such a way as to ensure the achievement of an organization's marketing objectives. The elements of marketing mix have been classified under four heads - product, price, place and promotion, usually known as the 4P's (McDonald, 2002).

Like McDonald (2002) in relation to interrelated elements that make up marketing strategies, the first and most important element is product/market selection .This deals with the markets the organization in question would want to serve with their product lines.

Price is second critical element answers the question; What prices will be set for individual products; how will products in the line be priced relative to each other; will we offer quantity discounts, deferred payments plans and or rental options; what kinds of price promotions will be needed to compete effectively.

The next element is the distribution system which comprised the wholesale and retail channels through which products and services move to the final users. They may constitute business entities such as the company's sales force, independent distributors, agents, as well as franchised outlets.

Marketing communications, a fourth element in marketing strategy, includes such components as print and television advertising, direct mail, trade shows, point- of- sale merchandise displays, sampling, and telemarketing.

In short, marketing mix involves decisions regarding products to the made available, the price to be charged for the same, and the incentives to be provided to the consumers in the markets where products would be made available for sale. These decisions are taken keeping in view the influence of marketing forces outside the organisation. 


\subsection{Porter's Generic Strategies}

Michael Porter according to Kotler (1997) has reduced marketing strategies into three generic types arguing that for a firm to sustain competitive advantage, it must have a strategy with which to resist the erosion caused by the competitive activities of its competitors as well as the ability to anticipate the changes within the industry within which it competes. The three generic strategies which Porter proposes could be a source of competitive advantage for the firms of low cost, differentiation and focus. Porter (1985) stated that competitive advantage grows fundamentally out of value a firm is able to create for its buyers that exceeds the firm's cost of creating it. Value is what buyers are willing to pay, and superior value stems from offering lower prices than competitors for equivalent benefits or providing unique benefits that more than offset a higher price. This implies that regardless of the many strengths and weaknesses a firm might have compared to its competitors, there are basically two types of competitive advantage that it can possess: low cost or differentiation. Originating from these is a third variation, the focus advantage which has two variants, cost focus and differentiation focus (Porter, 1985).

\subsubsection{Cost Focus}

With the low cost strategy a firm usually seeks economies of scale to bring down costs. This can be achieved if the organisation has access to proprietary technology or preferential raw materials. This would mostly mean low-cost labour and efficient training procedures in the service industries due to high labour turnover. According to (Porter, 1985) the products or services of low-cost firms are of a no-frills standard.

\subsubsection{Differentiation}

With the differentiation strategy, a firm seeks to be unique in certain dimensions that are valued by its customers, meaning that the elements chosen must be different from that of its competitors. Porter (1985) further explains that a firm can attain differentiation either through the firm's product, the delivery system, the marketing approach as well as a range of other factors. Compared to the cost leadership strategy, a firm through differentiation can add value to products and services putting itself at a sustainable competitive point where it would be difficult for competitors to copy. One of the key methods through which differentiation can be achieved is through brand loyalty.

\subsection{General Perspective of Design}

Design from an organisational perspective, does not operate in isolation, but in relation to a range of different disciplines, organisational units and functions i.e. marketing, research and development, production, engineering, finance, law and brand management. Depending on their level of 'design literacy', organisations tend to view design in one of several ways: in terms of aesthetics (look and feel); as a process; as a response to users' needs; or (increasingly) as a strategic business component or tool.

According to Candi, (2010) whereas the functional aspect can easily be understood as utility and performance; the aesthetic aspect of design is concerned with the visceral and 
experiential part that encompasses the human senses and meaning (Candi, 2010).

Heskett (2002) on the other hand suggests that like love, the meaning of the word design changes with respect to who is using it, in which context, and to whom or what it is directed. In his book Toothpicks and Logos, Heskett illustrates the versatile meaning of the term by saying that design is to design a design to produce a design. By this he means that design is a verb; indicating an action or a process and as a noun from three different: as a concept of a field as a whole, as an idea or a proposal, and as a final outcome or product though these three are mostly used interchangeably.

Now in a situation where design is used as communication, it is important to understand how design conveys meaning to the consumer. The alignment of a customer's self image or expectations with that of the product or organisation is done by design. Mass media critic Tony Schwartz (1974), in talking about the effects of television and radio on consumers, wrote that the critical task is to design our package of stimuli so that it resonates with information already stored within an individual and thereby induces the desired learning or behavioural effect. Resonance takes place when the stimuli put into our communication evoke meaning in a listener or viewer. That which we put into the communication has no meaning in itself. The meaning of our communication is what a listener or viewer (or in the case of design, the consumer) gets out of his experience with the communicator's stimuli. The listener's or viewer's brain is an indispensable component of the total communication system. His life experiences, as well as his expectations of the stimuli he is receiving, interact with the communicator's output in determining the meaning of the communication. Therefore, to achieve a behavioural effect, whether persuading someone to buy a product or teaching a person about history, one designs stimuli that will resonate with the elements in a communication environment to produce that effect.

Kotler and Rath (1984) provide the best definition of design as a strategic marketing weapon. "Design is the process of seeking to optimize consumer satisfaction and company profitability through the creative use of major design elements (performance, quality, durability, appearance, and cost) in connection with products, environments, information, and corporate identity" (Kotler \& Rath, 1984). Kotler and Rath (1984) through the description break the value of design as a marketing tool down into its major elements to bring out the best understanding. With the performance aspect, designers to determine and understand the wants and needs of the target market, gather information through market research. Through the research, designers are often credited with developing features that enhance the product in ways that may never have occurred to the consumer. John and Linda (1976) identified two types of performance characteristics; instrumental performance and expressive performance.

Instrumental performance is the functional expectations consumers have for a product. It answers the following question; does the product serve its intended purpose well and satisfy consumer need?

Expressive performance on the other hand is the psychological level of performance answering the question; does the product create and arouse consumer need? 
Design's performance role is not limited to only products. This is because consumers can either be satisfied or dissatisfied with the instructions for assembling or using a product (information design), a store layout (environment design), or even with a company's ability to live up to or surpass expectations promised by its corporate identity. Swan and Combs (1976) found that, in judging the performance of a product, the consumer compares a set of performance outcomes to the outcomes that were expected for the item. If the performance of the physical product was below expectations, then the product is likely to be categorized as dissatisfactory. If both instrumental and expressive outcomes were equal to or exceeded expectations, then the consumer will in tend judge the product as satisfactory.

Therefore the purpose of using design is to help discover the desired level of performance in a product and communicate appropriate levels of expectations to the consumer. This implies that whether an item is generic or premium positioned, its high-quality design is just as important since it communicates to the consumer exactly what it is that they are buying as well what their expectations should be for the products performance.

According to Hauser and Gausing (1988), products should be designed to reflect consumer's desires and tastes - there is then the need for marketers, designers and manufacturers to work closely with each other through the whole marketing process; from developing the product idea through production and distribution and finally through research to determine consumers' satisfaction, which is input back into the product development process. Design plays a critical role in this cyclical process referred to as "continuous-improvement (Gitlow \& Gitlow, 1987). That is why Urban and Star (1991) describe design as an integral part of "total quality":

\subsection{Design Thinking}

The term design thinking is generally referred to as applying a designer's sensibility and methods to problem solving, no matter what the problem (Lawson, 1997). It is not a substitute for professional design or the art and craft of designing, but rather a methodology for innovation and enablement (Brown, 2009). Design Thinking can therefore be described as a tool to aid the process of discovering unmet needs, opportunities, create new solutions and reinvention as well as transform businesses. It embraces a problem solving perspective instead of getting trapped with the constraints and former arguments that goes with solving problems and also transforming organizations. Supporting that, Anna Rylander said that, “This discourse typically emphasizes designers' passionate "mind-set” (Dunne \& Martin, 2006) or a "design- attitude” (Boland, 2008; Boland \& Collopy, 2004) that does not worry about constraints, but is rather an on-going expectation that each project is a new opportunity to create something remarkable and in a way that has never been achieved before.

Tim Brown mentioned in a speech that, now a day's thinking out-of -the -box is even not enough any longer to generate breakthrough ideas (TED, 2009). Contrary to the old, traditional management styles and their methods which are restricted by financial analysis and analytic approaches, Design Thinking provides proactive tools and methods to cope with the risks that would rise without prediction 
Design Thinking has created excitement among a lot of people previously untouched by design, and this has generated new opportunities for designers to engage with business management, and other functions and levels within the organization (Lockwood, 2009). Design Thinking is based on matching balance between three overlapping main criteria in order to achieve breakthrough success and they are as follows: design thinkers need to analyze what is technologically feasible (what can be produced), what is economically viable and finally what meets the human needs, in other words what is socially desirable (what should be produced) (Clark \& Smith, 2008; Brown \& Katz, 2009). These criteria are also offered as tools for non-designer managers in various organizations to implement the problem- solving approach of Design Thinking.

\subsection{Design Thinking Process}

The processes that Design Thinking follows can be best described as developing deep consumer insights, rapid prototyping and seeking radical innovation as well as empowering teams to be innovative (Brown, 2008). The first goal of Design Thinking is to understand what is meaningful to consumer and discover unarticulated needs. Next to bring clarity to the gathered data by producing rapid prototypes, using mock-ups, storyboards, storytelling method, user testing, and even by acting out concepts and services. The intent is to reduce the risk of failure and accelerate organizational learning as an iterative process. Design thinking methodology consists of three phases. While Fraser (2009) calls them gears, Tim Brown (2009) has named them as the 'Phases of the Innovation Process: Inspiration, Ideation and Implementation'.

\subsubsection{Inspiration}

The inspiration phase requires different sets of skills and methods to achieve market insights, contrary to traditionally market researches and surveys that most of the practitioners used to apply (Brown, 2008). In order to formulate problem statements, designers look to people's behaviour for the insights they need. Specifically, observation and empathy are the complementary elements of the inspiration phase. These newly offered methods can be considered as more ethnographic, qualitative methods that designers tend to use to help explore and generate new ideas (Brown \& Katz, 2009).

As a successful chief designer of an American company once stated that by analyzing and using consumer research, all creativity is driven out of the product and that no good product was ever created from quantitative market research. Great products spring from the heart and soul of a great designer, unencumbered by committees, processes or analyses (Martin, 2009). Arguments of Brown and Katz (2009) stated clear support for his remark by saying that traditional techniques such as focus groups and surveys, which in most cases simply ask people what they want, rarely yield important insights.

\subsubsection{Ideation Phase: Building to Think}

Ideation is the second proposed phase of Design Thinking and its main element is brainstorming. As important as brainstorming is, generating game-changing ideas through divergent and convergent processes and building interdisciplinary teams are also relevant for 
the success of ideation phase (Fraser, 2009; Brown, 2008).

Design Thinking embodies both divergent and convergent thinking, which can also be described as analysis and synthesis (Fraser, 2009; Brown, 2008). Incorporating these two distinctly thinking ways is basically a transition from creating and making choices to choosing amongst the alternatives that have been created through synthesis and divergent thinking.

Boland and Collopy (2004) stated that the design of the system is no longer contained in the head of a single individual or group- rather, it is emergent across multiple individuals or groups. Nevertheless, it could be argued that having such a varied and rich source of disciplines can create problems for coordination and integration (Noyes \& Baber, 1999). However, as Tim Brown (2005) argues, brainstorming within interdisciplinary groups can produce faster and better ideas. Accordingly, creating prototypes is the other important contribution to Design Thinking. Prototyping is a facilitator for brainstorming, as well as acquiring and improving ideas. As reinforced by Brown and Katz (2009), rapid prototyping allow designers to make their ideas tangible faster so that they can evaluate, refine them and more importantly zero in on the best solution sooner.

\subsubsection{Implementation Path from Project Room to the Market}

In the third and final phase of innovation is implementation. Design-thinkers are mostly concerned with communicating an idea with sufficient clarity to gain acceptance across the organization, providing it, and showing that it will work in its intended market (Brown \& Katz, 2009). However, many obstacles are usually presented at this stage; good ideas can be rejected by commercial restrictions or by a rigid organizational system. As is mentioned in Why Great Ideals Fail, successful products have to navigate a complex path making the idea and initial design is only one piece of the story (Norman, 2010).

To mitigate this problem Brown (2008) offers the story telling method. According to him, if organizations aim to increase the likeliness of survival of the idea, they need to address influential, clear, strong stories with their ideas. Well constructed, expertly communicated stories can help design thinkers to illustrate, show and build emotional links with the idea itself and the decision-makers to gain their commitment and support (Brown, 2008).

\subsection{Design and the Marketing Concept}

Design is the visual expression of the marketing concept. In that through research, design determines what it is that the target market wants and translates that back into products, environments, information or corporate identity for the consumers' benefit, using the elements of performance, quality, durability, appearance and cost. This section will investigate the "why" of design for marketing.

By nature, designers are concerned with the basic properties of the raw materials in a product, not for what they are but rather for what they might become in terms of satisfying human needs. Design therefore becomes the outward expression of the manufacturer's regard for both the products it makes as well as for the consumer. That is why Dichter (1975) says that a 
good design is an expression of considerateness on behalf of the organization to the consumer.

Many a time, consumers prefer to do business with a company that genuinely cares about them. Peters and Waterman (1982), in their book In Search of Excellence, they noted that many companies talk a lot about how important customers are, but actually think of them as a "bloody nuisance" and treat them accordingly. Design, the visual expression of the marketing concept, should therefore be well managed and coordinated to allow an organization achieve its goals. Design is a subtle, genuine expression of caring for the consumer and is absolutely essential to their satisfaction because it customizes information to suit their needs hence the saying actions speak louder than words.

\subsubsection{Design and the Marketing Mix}

Like goals of an organisation, marketing objectives are what any company would want to achieve. A company's plan for how it will go about achieving its marketing objectives is marketing strategy. The tool that a marketer works with to help an organisation achieve its goals is the marketing mix (Kotler, 1991).

According to Pride and Ferrell (1983) the marketing mix is made up of four "controllable" components that surround the consumer in a marketing-oriented firm: product, price, place and promotion. These components interact with the marketing environment: political, legal, regulatory, societal, economic and technological forces over which the marketer has little or no control. By the implementation of design as a positioning and differentiating strategy, the marketing mix and the marketing environment are affected positively.

The product component has to do with all physical characteristics of the new product design. Lawless and Fisher (1990) further divided the product component into function and form characteristics, indicating that, from a managerial perspective, they represent different investment approaches

The intangible aspects of a product are its non-physical characteristics that affect the customer's perception of the total offering (Lawless \& Fisher, 1990). Levitt (1981) states clearly that the intangible parts of products are of importance to innovation, further describing the difference between product tangibles and intangibles through this illustration. An automobile is not simply a machine for visible movement neither is it differentiated only by design, size, colour, options, horsepower, or miles per gallon

Image branding and packaging is either considered as product or promotion variables. It is therefore the job of graphic and industrial designers' to make sure that the satisfaction promised by product's are safely and effectively carried through shipping and handling, onto retailers' shelves and into consumers' homes, and then into recycling bins instead of landfills. Graphic designers communicate information about a company or its products in the promotion variable of the marketing mix, which may include advertising, point-of-purchase displays, packaging labels, annual reports and corporate identity. If well communicated, an image should be able to help establish a company's character and position in the minds of its customers shield the company from its competitors as well as enhance market performance. 
This is because the potential of impact design has on a company's performance of design on a company's performance draws attention to the importance of managing the image over time. Contrary to the market-share mentality that dominates the thoughts of marketers, brand image or corporate identity according to Park et al. (1986) should be viewed as a long-term investment of an organisation. In communicating a brands image, design plays a major role and as such should be managed as a strategic competitive tool as well. Explaining the role of design in marketing communications, Blackwell (1987), a marketing professor at The Ohio State University, puts it this way: "All aspects of an organization's activities are focused upon satisfying the customer in a marketing-oriented firm. The same applies to the communications to those consumers. Thus, product design is seen as part of the communications program, as is package design, the decoration of the truck fleet, the uniforms worn by employees, the corporate logo, and the annual report".

The place variable of the marketing mix deals with architects, retail planners and interior designer's impact with regards to attractive, productive, safe and comfortable office, warehouse and retail environments for employees and consumers.

The final variable, price is determined by the perceived value (innate qualities) of the product and its appropriateness for its intended purpose by the consumers. The enhancements or efficiencies gained in the course of manufacturing as a result of good industrial design may give a company the advantage of either charging more for a product because of its appearance and functional qualities or to even compete at a strategically low price.

Companies through design gain competitive advantage in the marketing environment. Apart from communicating a company's position regarding political, legal and regulatory forces it is also dynamic in responding to issues confronting the organization whether economical, technological or societal. Although marketing environment variables may be uncontrollable, with design the organisation can anticipate as well as respond to consumer's needs. Through all variables of both the marketing mix and marketing environment, design communicates information about a company or its products, providing consumer satisfaction and also helping corporations achieve their objectives. There is therefore the need for design to be managed with the same importance as the other marketing mix elements.

\subsubsection{Design and Marketing Strategy}

Gorb (1990) says that as a powerful tool design could be used by managers to make and sell products, develop an effective working environment, or even serve as a form of communication to consumers, shareholders and employees just like they do advertising or public relations. Though every company to some extent makes use design, only a few fully employ the services of the designers from the beginning stage of the product till it's done. Caplan (1982) believes that for a design to be good there is the need for each decision taken to be reinforced by other marketing decisions.

'The marketing process consists of analyzing marketing opportunities, researching and selecting target markets, designing marketing strategies, planning marketing programs, and organizing, implementing, and controlling the marketing effort (Kotler, 1991). 
Kotler and Rath (1984) said that a well-managed, high-quality design offers the company several benefits. It can create corporate distinctiveness in an otherwise product- and image-surfeited marketplace. It can create a personality for a newly launched product so that it stands out from its more prosaic competitors. It can be used to reinvigorate product interest for products in the mature stage of its life cycle. It communicates value to the consumer, makes selection easier, informs, and entertains. Design management can lead to heightened visual impact, greater information efficiency, and considerable consumer satisfaction.

Clipson (1990), a leading proponent of design management adds that, "All outcomes of design are imbued with some symbolic or emotive content; this applies equally to a product, a building, a communication or a service.... In consumer personal products the emotive content is high, while in industrial goods it may be much lower; however it is always present".

Design-Thinking as a marketing strategy can run through the human-centred approach to innovation provide a lens that would shed more light on creativity as well as allow design thinkers to zoom in and out of the design process iteratively. This is because ''In today's unpredictable rapidly changing environment, companies which can become agile, empower creativity, innovative, able to understand the values of their customers and stockholders, and integrate all aspects of business, society and technology will reap the benefits of incorporating the design thinking principles to their organizations” (Brown \& Katz, 2009).

\subsubsection{Design Management}

Deciding, managing, organising and facilitating how design can play a transformational role, how design processes can connect to business processes, and how design strategy can support business and organisational strategy, are some of the areas of competencies of design management.

Four contexts in which design management can be used (how to manage designers, designers in a management society, design function in an organization, and how managers use design), and a design user's model discussing four levels of a corporation's interaction with design (product, environment, information and corporate identity) will also be examined.

Gorb (1982) defined what design is for managers and why it should be important to them. Design is the planning process for the things you make (which are your products). It can, but need not necessarily be, concerned with the aesthetics of your product.

Kotler's (1984) observations on design management support this four-tier structure proposed by Gorb. Bill Hollins and Stuart Pugh (1990) refer to the integration of these four levels as "total design - the systematic activity necessary from the identification of a market of user need to the selling of the successful product to satisfy this need".

Design managers should be responsible for coordinating and directing all four levels of an organization's design efforts: products, environments, information and identity, in the same way that the personnel or accounting departments are managed.

The first level is the product, the most important and most immediate concern for the manager. This level should include all activities from market research input through the start 
of detailed product specifications and designing, into and through manufacturing (Hollins \& Pugh, 1990). Glen Urban and John Hauser (1980) take a similar view of the product design process, "Design is the designation of the key benefits the product is to provide, the psychological positioning of these benefits versus competitive products, and the fulfillment of the product promises by physical features".

The second level is the environment. Environment design encompasses tools, buildings, equipment, location, vehicles, and selling points. Disciplines involved with environment include architects, retail planners, interior designers, site planners, landscape architects, signage designers and graphic designers.

The third level of the design model, information, is where design is typically thought of as communications. Information design may encompass everything from management information systems to advertising and public relations, to annual reports and signage. Gorb (1982) points out that because the costs of information design are slight; managers tend to trivialize the task. This is especially problematic when you consider that this is what most influences the public when they evaluate a company.

The fourth level of design input to an organization is corporate identity. Gorb (1982) says this level affects major management issues of strategy and policy. Corporate identity design involves auditing, improving, standardizing and controlling the product, environment and information systems which are used to communicate a company's personality, culture and mission. The most important point is that design, at all four levels-product, environment, information and corporate identity-must be integrated. Otherwise, it represents the short-sightedness of "selling" as opposed to true "marketing."

Peter Lawrence, founder of the Design Management Institute, feels that developing a design management discipline falls into two parts: developing the organization and operating structure within corporations to take better advantage of design's benefits; and promoting understanding by senior and middle management and integrating design at policy level (Design, 1982).

Recognition of design's importance to business has risen in past decades, since Kotler and Rath urged business leaders to revise their view of design as a cosmetic, decorative treatment applied late in development. Instead they should recognise how it can "optimize customer satisfaction and company profitability and value and enhance products, environment, communications and identity” (Kotler \& Rath, 1984).

\subsection{The Value of Design as a Strategic Tool}

Porter's generic value chain describes an organisation's internal environment in terms of primary and support value activities. The value and associated cost of each are assessed with a view to maximising the former and minimising the latter (Porter, 1985). The value chain is interesting when considering an integrated design ethos; Lorenz (1994) noted that Porter only recognised design in its technological sense, as a primary activity in 'operations' and 'technology development'. This might be extended to include communication design in marketing, represented as separate activities within each of these, in "their traditionally 
subservient role” (Lorenz, 1994).

More currently, design's greater value is seen as resulting from an integrated effort of many areas of design specialisation (graphic, interactive, industrial) concerted across operations (Kotler \& Rath, 1984; Phatak \& Chandron, 1989). A design-led view argues that design can be applied to the other activities, not just the product, to improve the quality, user satisfaction and even the image of the other value stages. Few academic papers have explicitly considered design's place in the value chain. In one, Borja de Morzota (2003) finds design acts at three levels in the value chain, as simultaneously a differentiator, co-ordinator, and transformational process.

- $\quad$ By optimizing the primary activities: design action on the consumer perceived value.

- By optimizing the coordination among functions and the support activities of the firm: design as a new function in the structure that transforms the management process.

- By optimizing the external coordination of the firm in its environment: design generating a new vision of the industry (Borja de Morzota, 2003).

Understanding and creating perceived value draws on the core expertise of the designer, but quantifying it in Porter's terms is difficult when much is in the intangible values of goods and services (Kotler \& Rath, 1984), and for two other reasons.

First, there are many essential contributions to the design process that come from non-designers and are unacknowledged. Gorb and Dumas (1987) coined the term silent design for "design by people who are not designers and are not aware that they are participating in design activity”, a phenomenon that can be both detrimental and beneficial (Dumas \& Mintzberg, 1991).

Second, the contributions of design professionals to business success are often "invisible and rarely acknowledged”, enhancing performance in “associated 'non-design' areas where they are not considered to have any interest, let alone competencies"- a sort of 'silent design in reverse’ (Topalian, 2002).

\section{Research Methodology}

This chapter provides the research design, population, sample size and sampling technique, data collection instrument, data analysis plan as well as a brief introduction of the study organization.

\subsection{Research Design}

A research design outlines the way in which one approaches the research throughout the study (Ringdal, 2001). Research can either be qualitative or quantitative in approach and the type of approach used would depend on the defined problem and the investigated type of data that can be used to solve the problem (Creswell, 1998). Unlike quantitative research, which is characterised by selectivity and distance between the researcher and the source, qualitative research is characterised by closeness to the respondent or source and intends to capture values, attitudes and perceptions regarding the investigated area. Therefore the researcher 
strives to obtain a complete understanding and overview of the problem rather than just focusing on certain specific variables (Holmes \& Solvang, 1997).

The researcher chose a qualitative approach, employing a comparative and descriptive design. Using both deductive and inductive strategies the researcher intended to capture values, attitudes and perceptions regarding how design thinking could be used as marketing strategy for CPC. The deductive approach was suitable to establish and develop research questions and a theoretical framework based on previous theory, and would also be used in chapter 4 and 5 to form the foundation of how the analysis was to be performed. An inductive approach on the other hand would be used in the analysis to inform and expand on the theory. Employing a descriptive design was well suited for the topic as it would illuminate fields like design thinking which has been subject to little previous research.

\subsection{Population of the Study}

A research population according to Ghauri and Gronhaug (2005) relate to the total universe of units from which the sample is to be selected. The population of the present research comprised management personnel within the organization of study thus Cocoa Processing Company Limited, Tema and a cross section of its customers in Tema. Now the population size was made up of management personnel from the marketing, production as well as the research and development departments and CPC customers.

\subsection{Sample Size and Sampling Technique}

Decisions about where to conduct researches and who to include (what is traditionally called "sampling”) are an essential part of research methods. Miles and Huberman (1984) cleared the mind of researchers by saying: "Knowing that one cannot study everyone everywhere doing everything, even within a single case, how does one limit the parameters of a study?”. According to the authors, if researchers are selecting one kind of informant, they need to consider why this kind of informant is important, and from that point, which other candidates should be interviewed. Consequently, the present paper has chosen the 8 participants based on the corroborative statements of Miles and Huberman in order to have representative and relevant participants even within the limited scope of time and resources.

Also according to Morris Evans (1986), for very small populations (50 or less), there is the need to use the entire population in order to achieve accuracy, hence the use of the whole population as the sample size in the study.

In justifying the sample size mathematically, a model was used its calculation as shown below:

$$
\begin{aligned}
& \mathrm{n}=\underline{\mathrm{x}^{2} * \mathrm{~N} * \mathrm{P}(1-\mathrm{P})} \\
& \mathrm{ME} *(\mathrm{~N}-1)+\left\{\left(\mathrm{X}^{2} * \mathrm{P} *(1-\mathrm{P})\right\}\right.
\end{aligned}
$$

Where

$$
\mathrm{n}=\text { Sample size }
$$


$\mathrm{x}^{2}=$ Chi-Square for the specified confidence level at one degree of freedom

$\mathrm{P}=$ Population proportion ( 0.50 in this table )

$\mathrm{N}=$ Population size

ME = Desired Margin of error ( Expressed as a proportion )

Source: Krejcie and Morgan ( 1970 )

Substitution:

$$
\begin{aligned}
\mathrm{n}= & \underline{1.96^{2} * 8 * 8(1-0.50)} \\
& 0.05^{2} * 7 * 1.96^{2} * 0.5 * 0.5 \\
= & \underline{7.84} \\
& 1.715 \\
= & 4.57
\end{aligned}
$$

The calculation above had shown that a minimum sample size of four could have been used for the study but all the entire population of ten was used for the analysis.

Strategic decisions are usually taken by top management, hence, for the purpose of this study; the researcher used the purposive sampling method to select eight (8) top management personnel as respondents out of the population size. Two (2) participants each were picked from three departments within the organization of study namely; marketing, production and research and development and two (2) customers within Tema metropolis who had the knowledge and were willing to share their experience.

The purposive sampling technique, also called judgment sampling, is the deliberate choice of an informant due to the qualities the informant possesses. It is a non-random technique that does not need underlying theories or a set number of informants. Simply put, the researcher decides what needs to be known and sets out to find people who can and are willing to provide the information by virtue of knowledge or experience (Bernard, 2002; Lewis \& Sheppard, 2006). The key informants used are observant, reflective members of the community of interest who know much about the culture and are both able and willing to share their knowledge (Bernard, 2002).

\subsection{Data collection Instruments}

A hallmark of case study research is the use of multiple data sources, a strategy which also enhances data credibility (Yin, 2003). This thesis combined approaches of both primary data and secondary data sources. The primary data was in a form of an interview with key individuals within the organization and the secondary data were also culled from the company's reports, internet as well as the product fliers of the organisation. Having multiple sources of data helps secure the reliability of interviews, and minimize the risk of having some answers misinterpreted (Ringdal, 2001). 
The interview started with the researchers presenting an overview of the research, what is to be discussed and why the organization under study was used as a case study. The proceeds of the interview were captured on tape but two participants had to be interviewed on phone due to their busy schedule on the day the interview was conducted. According to Yin (1994), to register the empirical data with an absolute accuracy during an interview is essential hence the need of a recorder. So permission was sought from all respondents with the exception of one to have the interviews recorded.

In addition to the in-depth interviews, the researcher also made use of information from Cocoa Processing Company's web pages, annual reports and also previous related research works on design thinking that others had done on the internet.

This convergence adds strength to the findings as the various strands of data are braided together to promote a greater understanding of the case (Patton, 1990; Yin, 2003).

\subsection{Data Analysis}

In analysing the data, the researchers made use of an analytic technique called pattern matching, where patterns observed from each interview would be compared with patterns from the others and those predicted by the theoretical model (Yin, 2003). With this approach the researchers were able to identify similarities and differences between the views of the various interviewees and compare that with the theoretical framework on design thinking.

\subsection{Validity}

Validity is the extent to which the researcher is able to study what he or she had sought to study rather than something else (Gummesson, 2000). More specifically, construct validity establishes correct operational measures for the concepts being studied (Yin, 1994). Furthermore, he states that there are three different tactics to increase construct validity. The first tactic is the use of multiple sources of evidence during the data collection. The second tactic is to establish a chain of evidence. This is based on the principle to allow an external observer to follow the derivation of any evidence from the initial research questions to the conclusion of the case study. The third and last tactic is to have the draft cases study reviewed by key informants (ibid).

In this study, the researchers followed all the recommendations from Yin (1994) to increase the construct validity. The researcher collected data by interviewing two persons from three departments within the organization to help triangulate the data to be analysed. Also the researcher made use of multiple sources of evidence i.e. conducted an interview as well as used other supporting documents. Furthermore, in order to create strong chains of evidence, the researcher throughout this study made citations to all sources from where evidence has been collected. This was done to make it possible for any external observer to follow any evidence throughout the study.

\subsection{Reliability}

Reliability demonstrates that the operations of the study such as data collection procedures can be repeated with equal result. Now should a researcher repeat the exact same procedure 
and research as described by an earlier researcher should arrive at the same results and draw the same conclusions (Yin, 1994). In order to obtain a high degree of reliability, the researchers had in this article carefully explained the procedures of the research so as to minimise errors.

\subsection{A Brief Description of the Study Organisation}

Cocoa Processing Company Limited (CPC) was established in 1965; it is situated in the picturesque port city of Tema in Ghana on the Greenwich Meridian (Longitude 0). The company comprises three factories: two Cocoa Factories and a Confectionery Factory. Cocoa Processing Company Limited is a limited liability company incorporated in Ghana on November 30, 1981. The shares of the company are publicly traded on the Ghana Stock Exchange.

The Cocoa Factories have an annual throughput of 64,500 metric tonnes of Premium Ghana Cocoa beans which it processes into Cocoa Liquor, Cocoa Butter, Cocoa Cake and Cocoa Powder. These semi-finished products are the major ingredients for the production of chocolate and other cocoa-based food products. The semi-finished products are sold under the Portem brand name to foreign markets. The company however retains a portion of the semi-finished products for use in the Confectionery Factory. The Confectionery Factory manufactures chocolate confectionery namely, chocolate bars, chocolate spread, drinking chocolate and chocolate dragees. The confectionery products are marketed under the brand name Golden Tree.

The CPC factories process only the choicest premium Ghana cocoa beans without any blending, probably the only factory in the world which can make such a claim. Through intensive research and product development, CPC turns out products, which meet international quality standards and also consumer satisfaction.

\section{Findings and Discussions}

In this chapter, findings from the empirical research used to answer the research question, 'how the Design Thinking process could be used as a strategic marketing tool by Cocoa Processing Company' was analysed under the following core units: marketing strategies, Porter's generic strategies and the design thinking process. The response rate was $100 \%$ since the researcher used the purposive sampling method. This implied that all participants were picked because they had needed knowledge and were willing to share their experience.

\subsection{Demographics of the Participants}

Cocoa Processing Company is made up of these departments: Engineering, Quality Control, Marketing, Accounts, Procurement, Human Resource, Audit, Production- Cocoa, Production Confectionery and Research \&Development. For this research, data was gathered, from Local section of the Marketing department which deals with the sales of confectionery products, Production- Cocoa and Production- Confectionery and the Research and Development departments. Demographic data were compiled according to the characteristics needed for this particular research study. Participants within CPC were picked based on their years of 
experience within the various departments and also the level of knowledge within their various departments as well as those of other departments they integrate with to come out with products to be offered to customers. The customers were also picked based on the number of years they have either worked with CPC as distributors or patronised their products on the retail level.

\subsection{Level of Integration among Departments at C.P.C}

Majority of respondents within the organization revealed that C.P.C was market driven organisation. It was realised that Research and Development (R\&D) develops the recipe, Production pilot tests after which they are finally sent to Marketing Department to market test for customers' reactions. If the response is encouraging, then it would be implemented if not then it would be abolished. So by and large it was the R\&D that brought products on board. It also came out that before any product is offered, a though a consensus is built within the various departments in the organization as to the decision on what product to bring to the market, the trigger mostly came from the Deputy Managing Director (DMD). The findings were in consistent with Lockwood (2009), who observed that 'the power of interdisciplinary teams is undeniable, and the ability of design teams to see the entire picture and context as well as the details of it make Design Thinking approach rather unique. The level of integration among the various departments also account for the success of the organisation

\subsection{Development of Products to Meet Consumer Needs}

It was revealed from the study that its $R \& D$ department developed products and then pilot tested to see consumers' reactions before they were brought into the market. Though there were times when products offered were from the customer's point of view, such products were based on customers' specifications. As one responded indicated, 'we have done 2 different recipes just for Japan, 3 or 5 for the US market, and then we also have a special recipe just for Nigeria, and even in-house thus locally we have soft pebbles we have developed for a customer. The revelations were in consonance with Hauser and Gausing (1988), who observed that products should be designed to reflect consumer's desires and tastes.

This is enough proof that since customers get value for their money's worth, there is no form of agitation over what they had to pay for CPC products. The next element is the distribution system or the place variable. Place decisions are those associated with channels of distribution that serve as the means for getting the product to the target customers. The distribution system performs transactional, logistics and facilitating functions. Distribution decisions include market coverage, channel member selection, logistics, and levels of service.

It was realised that CPC gets its products to its customers through major key distributors all over the country who are recruited based on CPC's standards and majority of the respondents attested to that. For further elaboration, one respondent said that, 'CPC recruits through an open system by asking the general public with the interest and resources to apply. Some of these standards include details of one's capacity to stock large volumes of their products and an evidence of VAT registration. 'A field trip is then taken by a marketing officer and a 
Quality Assurance officer to check the location and marketability of the shop and other things like the temperature of the place and the kind of products sold there. All this was done to ensure that products sold to the final consumer were safe for consumption'.

\subsection{Product Differentiation from Competitors}

With reference to Porter's generic strategies, an organization, regardless of its many strengths and weaknesses as compared to that of its competitors can gain competitive advantage either through low cost or differentiation. The study revealed that CPC products were made from $100 \%$ premium cocoa from Ghana with no cocoa butter substitutes unlike its competitors. It was further explained that the high quality of Ghana's cocoa beans was attributed to the consistency and the agronomical practices of the farmers in Ghana. The results were found to be consistent with Porter's observation in 1985, who stated that competitive advantage grows fundamentally out of value a firm is able to create for its buyers

From the interview, it was deduced that 'CPC was also the only company worldwide that produced chocolate at the highest and lowest melting points. 'We are the only company that develops chocolate that can withstand hot temperate zone like those in Africa and also produce to withstand the cold temperate zone in Europe as well'. Unfortunately, no deliberate effort was being made to capitalize on such strength to market the products. The fact that 'CPC uses its own semi-finished products and converts them into its confectionery product was also another plus since the quality of raw materials would always be assured and this gave them an added advantage over others who were also into the production of confectionery products'. Also the health benefit of CPC's Royale Natural Cocoa Powder was a contributing factor differentiating it from all other competition. To corroborate this, CPC had it documented that it's Royale Natural Cocoa Powder had more antioxidants than in most natural foods. These antioxidants have been proven to help accomplish the following: decrease blood pressure, improve the function of endothelial cells that line the blood vessels, defend against destructive molecules called free radicals, which triggers cancer, heart disease and stroke as well as improve digestion and stimulate kidneys. So should a consumer take in Royale, he or she was expected to benefit from all that the antioxidants was capable of accomplishing. This alone should have been a striking power as an advertising brand which CPC could use in the marketing and advertising its product to the best of their ability.

\subsection{Design Thinking Process}

Marketing and production department would have to communicate with sufficient clarity to gain acceptance across the organization especially from management by providing the recipe and showing that it will work in its intended market. Respondent ' $A$ ' said that CPC had a product Innovation committee which coordinated the activities between marketing and the production, accounts and engineering. They met every fortnight to get updates on new developments with respect to its products and the way forward. According to Alexander Manu, author of The Imagination Challenge (2007), business needs to learn from design how to manage creativity from the inception of a concept through iterative stages to its implementation in products, systems, and services that are useful and desirable for a large group of people. Design needs to learn from business how to rigorously analyze the risks and 
rewards of any new creative idea and how to employ the tactics that will make it beneficial to users. It was surprising to note that all the above stages do not include designers. Design thinking requires the ability to embrace many different kinds of thoughts and knowledge -art, science and technology- and perhaps more importantly, the ability to integrate them (Utterback, 2006). Design thinking process also involves team approach, and the goal is to unlock the creative potential of the organization and its partners. With its unique and integrative characteristics "Design Thinking” has created excitement among a lot of people previously untouched by design, and this has generated new opportunities for designers to engage with business management, and other functions and levels within the organization (Lockwood, 2009).

Design Thinking is based on matching balance between three overlapping main criteria in order to achieve breakthrough success and they are as follows: design thinkers need to analyze what is technologically feasible (what can be produced), what is economically viable and finally what meets the human needs, in other words what is socially desirable (what should be produced) (Clark \& Smith, 2008; Brown \& Katz, 2009). Businesses are embracing design thinking because it helps them be more innovative, better differentiate their brands, and bring their products and services to market faster as in the case of CPC.

\section{Summary}

In summary, this section discussed how to explore the practicalities of the design thinking approach as a strategic marketing tool by CPC. The study has revealed that the organisation of study utilizes design thinking in some of its activities such as in its marketing strategies, the differentiation of its products from its competitors and also in the integration of the various departments within the organization. It was also noticed that in areas that had to do with the development of consumer insights in relation to the kind of products offered, CPC had some lacking. Moreover many people had little or no knowledge about the Golden Tree brand because CPC failed to capitalize on February $14^{\text {th }}$ which has been named national chocolate day by government to promote products it offers to the general public. Though designers were not mentioned in any of the activities undertaken by the various departments in the offering of products to consumers, CPC was encouraged to engage the services of designers since they are the bridge between the consumers and the organisation.

\section{Conclusion.}

In conclusion, the results of this study have revealed that, CPC through its Marketing, $R \& D$ and Production activities made no mention of any activities by designers. Meanwhile Brian Dumaine (1991) took note of the fact that managers within organisations looked upon design as pure aesthetics, a matter of simply dolling up a product long after it has been engineered ,typically failing to give designers enough authority to be effective. Meanwhile what they failed to see is good design addresses the consumer's every concern - how a product works, how it feels in the hand, how easy it is to assemble and fix, and even, in this era of environmental concern, whether it can be recycled. It remains that companies as diverse as Ford, IBM (Olins, 1985) and Sony (Lorenz, 1986) have achieved significant commercial success through their organization-wide use of design as a strategic marketing 
tool. This makes design critical to consumer satisfaction and corporate success. Therefore if marketing and design people understood and valued each other's methods, intentions and processes more clearly, then corporations and consumers would both benefit. Finally marketers and designers must learn to appreciate and respect each other's skills and realize they can achieve greater success through cooperation than through opposition.

\section{Acknowledgement}

All respondents are being acknowledged for providing information needed for this research.

\section{References}

Bernard, H. R. (2002). Research Methods in Anthropology, Qualitative and Quantitative Methods (3rd ed.). Walnut Creek, California: Altamira Press.

Blackwell, R. D. (1987). Integrated marketing communications. In G. L Frazier \& J. N. Sheth (Eds.), Contemporary views on marketing practice (Vol. 22, pp. 237-250). Lexington, MA: Lexington Books.

Boland, R. J., \& Collopy, F. (2004). Design Matters for Management. In R. J. Boland \& F. Collopy (Eds.), Managing as Designing (pp. 3-18). Stanford: Stanford University Press.

Borja de Mozota, B. (2003). Design management: using design to build brand value and corporate innovation. New York, NY: Allworth Press.

Bovee, C. L., \& Thill, J. V. (1992). Marketing. New York: NY: McGraw-Hill College.

Brown T., \& Katz B. (2009). Change by Design: How Design Thinking Transform Organizations and Inspires Innovation. New York: HarperCollins Publisher.

Brown, T. (2009). Change by design: how design thinking transforms organizations and inspires innovation. New York: HarperCollins Publishers.

Brown, T. (2009). Change by design: how design thinking transforms organizations and inspires innovation. New York: HarperCollins Publishers.

Candi, M. (2010). Benefits of Aesthetic Design as an Element of New Service Development. Journal of Product Innovation Management, 27, 1047-1064. http://dx.doi.org/10.1111/j.1540-5885.2010.00770.x

Chandler, A. Jr. (1962). Strategy and Structure: Chapters in the History of American Industrial Enterprise. Cambridge, MA: The MIT Press.

Clark, K., \& Smith, R. (2008). Unleashing the Power of Design Thinking Design Management Review, 19(3), 8-15. http://dx.doi.org/10.1111/j.1948-7169.2008.tb00123.x

Cocoa Processing Company. (2010). The Company: The Cocoa Processing Company. [Online] Available: http://www.goldentreeghana.com/the company.html

Creswell, J. (1998). Research Design, Qualitative, Quantitative and Mixed Methods Approaches (2nd ed.). Thousand Oaks, CA: Sage. 
Dichter, E. (1975). Packaging: the sixth sense? Boston, MA: Cahners Books.

Dumaine, B. (1991). Design that sells and sells and Fortune (pp. 86-94).

Dumas, A., \& Mintzberg, H. (1991). Managing the Form, Function, and Fit of Design. Design Management Journal, 2(3), 26-31.

Evan, M. (1986). Sampling from small populations.

Fraser, H. M. A. (2009). Design Business: New Models for Success. Design Management Review, 55-65.

Ghauri, P. N., \& Gronhaug, K. (2005). Research methods in business studies: A practical guide. Prentice Hall: Dorchester.

Gitlow, R. S., \& Gitlow, S. J. (1987). The Deming guide to quality and competitive position. Englewood Cliffs, NJ: Prentice-Hall, Inc.

Gorb, P. (1990). The future of design and its management. In M. Oakley, B. Borja de Mozota, \& C. Clipson (Eds.), Design management (pp. 15-25). Cambridge, MA: Basil Blackwell, Inc.

Gorb, P., \& Dumas, A. (1987). Silent design. Design Studies, 8(3), 150-156. http://dx.doi.org/10.1016/0142-694X(87)90037-8

Gummesson, E. ( 2000). Qualitative Methods in Management Research (2nd ed.). Sage, London.

Hauser, J. R., \& Clausing, D. (1988). The house of quality. Harvard Business Review, 66(3), 63-73.

Heskett, J. (2002). Toothpicks and Logos: Design in Everyday Life. Oxford University Press, USA.

Holme, I. M., \& Solvang, B. K. (1997). Research Methodology, Qualitative and quantitative methods. University Press.

Kotler, P. (1997). Marketing management: Analysis, planning, implementation and control (9th ed.). Upper Saddle River: Prentice-Hall.

Kotler, P., \& Rath, G. A. (1984). Design: A powerful but neglected strategic tool. Journal of Business Strategy, 5(2), 16-21. http://dx.doi.org/10.1108/eb039054

Krejcie, R. V., \& Morgan, D. W. (1970). Determining sample size for research activities. Educational and Psychology Measurement, 607-610.

Lawson, B. (2005). How Designers Think: Demystifying the Design Process. Jordan Hill, Architectural Press.

Lewis, J. L., \& Sheppard, S. R. J. (2006). Culture and communication: can landscape visualization improve forest management consultation with indigenous communities? Landscape and Urban Planning, 291-313. http://dx.doi.org/10.1016/j.landurbplan.2005.04.004 


\section{Macrothink}

Business and Management Horizons

ISSN 2326-0297

2014, Vol. 2, No. 1

Lockwood, T. (2009). Design Thinking, Integrating Innovation, Customer Experience, and Brand Value. New York: Allworth Press.

Lorenz, C. (1986). The design dimension: The new competitive weapon for business. New York: Basil Blackwell Inc.

Manu, A. (2007). The Imagination Challenge: Strategic Foresight and Innovation in the Global Economy Berkeley. California: New Riders.

McDonald, M. H. B. (2002). Marketing Plans: How to prepare them; How to Use Them (5th ed.). London: Prentice Hall.

Miles, M. B., \& Huberman, A. M. (1984). Qualitative data analysis: A source book of new methods. Beverly Hills, CA: Sage.

Norman, D. (2010). Design Thinking: A Useful Myth, Core 77 Design Magazine \& Resource.

[Online]

Available:

www.core77.com/blog/columns/design_thinking_a_useful_myth_16790.asp

Patton, M. Q. (2002). Quality research \& evaluation methods (3rd ed.). Thousand Oaks, CA: SAGE.

Peters, T. J., \& Waterman, R. H., Jr. (1982). In search of excellence. New York: Harper \& Row Publishers, Inc.

Porter, M. E. (1985). Competitive Advantage-Creating and Sustaining Superior Performance. Free Press, New York.

Ringdal, K. ( 2001). Unity and Diversity, Social Science research and qualitative methods. Oslo: Fagbokforlaget.

Schwartz, T. (1973). The responsive chord. Garden City, NY: Anchor Books.

TED. (2009). [Online] Available: http://www.ted.com/search?q=tim+brown

Topalian, A. (2002). Promoting Design Leadership through Skills Development Programs. Design Management Journal, 13(3), 10-18.

Urban, G. L., \& Star, S. H. (1991). Advanced marketing strategy: Phenomena, analysis and decisions. Englewood Cliffs, NJ: Prentice-Hall, Inc.

Utterback, J. M. (2006). Design-inspired innovation. Hackensack, N.J.: World Scientific.

Wind, Y., \& Robertson, T. S. (1983). Marketing strategy: new direction for theory and research. Journal of Marketing, 47, 12-25. http://dx.doi.org/10.2307/1251490

Yin, R. (1994).Case Study Research, Design and methods (2nd Ed.). Beverly Hills, CA: Sage Publishing.

Yin, R. (2003). Applications of Case Study (2nd ed.). Thousand Oaks, CA: Sage.

Zikmund, W. G. (1991). Exploring marketing research (4th ed.). Chicago, IL: The Dryden 
Press.

\section{Appendix: Interview Guide}

\section{Marketing Department}

Company name:

- $\quad$ Can you introduce yourself and tell me how long you have worked in the marketing department?

- $\quad$ How long has the marketing department being in existence?

- $\quad$ Can you take me through the activities performed by the marketing department?

- $\quad$ Describe the image or personality of CPC and the products it offers.

- Who is your target market?

- $\quad$ How often do you interact with your target market and through which distribution channels are your products made available to the target market/end users?

- Who and what determines the kind of confectionery products CPC brings into the market?

- $\quad$ Describe the unique characteristics of your products that distinguish them from the competition.

- $\quad$ Records have it that over the years CPC have been introducing new products into the market. I would like to know whether the initiative of introducing new products is based on the customer's views or that of the organization.

- What is the level of integration between the various departments within the organization? How does decisions taken within a department i.e. production or R\& D affect marketing?

\section{Production Department}

- Can you introduce yourself and tell me how long you have worked in the production department?

- How long has the production department being in existence?

- Can you take me through the activities performed by the production department?

- $\quad$ Describe the image or personality of CPC and the products it offers.

- Describe the unique characteristics of your products that distinguish them from the competition.

- Who is your target market? 


\section{Macrothink}

Business and Management Horizons

ISSN 2326-0297

2014, Vol. 2, No. 1

- Have there been instances where the production department has had an interaction with the target market/end user? What medium was used?

- Who and what determines the kind of confectionery products to be produced?

- Records have it that over the years CPC have been introducing new products into the market. I would like to know whether the initiative of introducing new products is based on the customer's views or that of the organization.

- What is the level of integration between the various departments within the organization? How do decisions taken within a department i.e. marketing or R\& D affect production

\section{Research and Development Department}

- Can you introduce yourself and tell me how long you have worked in the $R \& D$ department?

- How long has the R\&D department being in existence?

- Can you take me through the activities performed by the R\&D department?

- Describe the image or personality of CPC and the products it offers.

- Describe the unique characteristics of your products that distinguish them from the competition.

- Who is your target market?

- Describe any instance where the R\&D department had an interaction with the target market/end user? What medium was used?

- Who and what determines the kind of confectionery products to be produced?

- Records have it that over the years CPC have been introducing new products into the market. I would like to know whether the initiative of introducing new products is based on the customer's views or that of the organization.

- What is the level of integration between the various departments within the organization? How do decisions taken within a department i.e. production or marketing affect R\&D?

\section{Consumer}

- Can you introduce yourself and tell me how long you have been patronizing CPC confectionery products?

- Can you take me through the processes you pass through before you make a purchase?

- $\quad$ Can you describe the image or personality of CPC and the products it offers?

- Can you describe the unique characteristics of CPC's products that distinguish them from their competitors?

- $\quad$ Are you the end user of the product? 
- How often does CPC interact with customers and what medium do they usually use?

- From your point of view can you describe who and what informs your purchase?

- Records have it that CPC has over the years been introducing new products into the market. I would like to know whether you as a customer contribute to the knowledge behind the formation of new products.

- What do you think of CPC's relationship with customers?

\section{Copyright Disclaimer}

Copyright for this article is retained by the author(s), with first publication rights granted to the journal.

This is an open-access article distributed under the terms and conditions of the Creative Commons Attribution license (http://creativecommons.org/licenses/by/3.0/). 